\title{
Thanks to Our Volunteers and Friends
}

It is election time for the SIGCHI

Executive Committee (EC). I hope you will all vote, before May 31, for the six officers who will be leading SIGCHI for three years starting July 1 . Your vote is needed and will count.

Voting alone, however, is not enough to make SIGCHI run. In fact, it takes many dedicated volunteers to perform the diverse activities of SIGCHI. The EC is supported by appointed vice presidents (for publications, conferences, chapters, and operations) and appointed adjunct chairs whenever needed for pursuing visions of the EC (currently for specialized conferences, developing worlds, public policy, education, mentoring, awards, liaising with other societies, communities, and media and branding).

The vice president for conferences and the adjunct chair for specialized conferences lead the Conference Management Committee (CMC), which includes a core of nine people specializing in surveys, video captures, conference archives, reviews, and the submission process. In addition, steering committee leaders of our sponsored conferences are members and meet with the CMC to work on transferring information and improving the planning and management of our 18 conferences. And each of these conferences is run by a conference committee, reviewers, session chairs, student volunteers, and so on.

We also have a growing international public policy committee, a publications board and journal and magazine editors, and leaders for our 18 communities and 42 local chapters (the numbers are growing).

Many SIGCHI activities can only be successful if our volunteers manage to get support from groups, organizations, and individuals outside our organization. Let me provide a recent example:

Bringing CHI, our flagship conference, to Asia is an enterprise we considered and discussed for many years. It was only through the support of the Korean HCI Society that we managed to make it happen. It's worth noting that most of the 2,000 members of the Korean group are not (yet?) members of SIGCHI. The Korean HCI Society and SIGCHI have been coordinating to make it happen, and our Korean colleagues are extremely happy about CHI 2015 taking place in Asia.

However, in many ways, holding CHI in Korea competes with the existing annual Korean HCI conference: The Korean conference is normally held in February each year, only about two months before $\mathrm{CHI}$ in April!

The Korean HCI Society has worked aggressively to support CHI in Korea, navigating many disruptions to its own conference and practices. Indeed, it moved its 2015 conference three months earlier, to December 2014. This resulted in their having two conferences in the same year, and no Korean HCI Society conference in calendar year 2015.

CHI 2015 chose to hold the planning committee (PC) meeting in Seoul to begin the CHI 2015 cross-pollination. To entice PC members to make such a long trip, the Korean HCI Society moved its conference to Seoul, which cost double the amount of the usual location; scheduled the conference for just prior to the PC meeting; held a special track, called Premier CHI, on the final day in which CHI PC members presented their work; and provided lodging and food for PC members who participated in that special track.

In hosting 250 volunteers, logistics for the CHI PC meeting are equivalent to a small conference. Korean volunteers arranged to hold the PC meeting at Yonsei University, which helped keep costs manageable, and the Korean HCI Society submitted and managed grant requests to the Korean government to offset some costs at the PC meeting.

Even though the Korean HCI Society expended tremendous time and effort to hold a successful PC meeting, it provided even more support for the even greater challenges of organizing and running CHI 2015.

This is only one example. It shows how the success of many SIGCHI activities depends on SIGCHI volunteers and many others (our friends) contributing their time, their creativity, their expertise, and their resources. Representing the six SIGCHI officers that you elected three years ago, I acknowledge these contributions and thank our volunteers and friends. - Gerrit C. van der Veer President, ACM SIGCHI 